\title{
Education and Health in Developing Economies
}

\author{
Tom S. Vogl* \\ Princeton University and NBER
}

December 2012

\begin{abstract}
This paper reviews recent research on the relationship between education and health in poor countries. Multiple causal pathways link the two domains, across different phases of an individual's lifecycle and across generations in a family. Within an individual, childhood health enhances schooling outcomes, longevity incentivizes human capital investment, and education improves adult health. Across generations, the health and education of parents-particularly mothersboost both outcomes in their children.
\end{abstract}

*E-mail: tvogl@princeton.edu. I thank Jasmine Park for expert research assistance. 


\section{Introduction}

In the course of development, few processes are as intertwined with economic growth as human capital accumulation. Schooling makes workers more productive, speeds the development of new technologies, and better equips parents to raise skilled children, all of which promote economic growth. ${ }^{1}$ Growth, in turn, incentivizes investment in human capital. Causal links point in every direction, traversing phases of the lifecycle as well as generations.

The entangled role of human capital is not limited to aggregate income growth, however. Education exhibits complex dynamic relationships with several components of wellbeing, including health. For example, education affects health in adulthood; life expectancy affects educational investment in childhood; and the health and education of parents-particularly mothers-affect both outcomes in their children. Just as with income, these relationships are likely to be especially important in developing countries, where levels of both schooling and health are low but have risen rapidly over the past half-century (Becker et al. 2005, Barro and Lee 2011).

This chapter gives an overview of the current state of knowledge on the relationships linking health and education in developing countries. To emphasize the dynamic aspects of these relationships, the chapter will trace them out first within a generation, between childhood and adulthood, and then across generations, from parents to children. It will focus on reducedform evidence of these effects rather than efforts to precisely pin down mechanisms, for two reasons. First, the existing literature-especially that on developing countries-has simply

\footnotetext{
${ }^{1}$ Krueger and Lindahl (2001) review the links between education and development, with a focus on squaring microeconomic and macroeconomic evidence. Björklund and Salvanes (2011) describe the evidence, mostly from wealthy countries, on how parents' education affects the education of their offspring.
} 
generated more evidence on these reduced-form relationships. Mechanisms have received some attention (see, e.g., Cutler and Lleras-Muney 2010), but the evidence comes primarily from wealthy countries, and even that evidence remains sparse.

Second, the reduced-form evidence on dynamic links casts in stark relief the potential joint role of education and health in accounting for the intergenerational persistence of disadvantage. ${ }^{2}$ That is to say, the children of unhealthy and uneducated parents grow up to be unhealthy and uneducated parents themselves. Others have proposed similar arguments about the intergenerational dynamics of the relationship between health and socioeconomic status, more broadly construed (Cutler et al. 2011, Currie and Vogl forthcoming). But the links between education and health, which typically lie at the crux of these arguments, can by themselves account for the dynamics. Given the current extent of inequalities in income, human capital, and health in developing countries, the links between education and health may prove important in shaping long-term trends in the levels and distributions of both variables.

Associations between health and education are not new, but with such tangled causal pathways, these associations sometimes prove to be uninformative. ${ }^{3}$ The recent literature in economics has made its main contribution in causal inference. Analyses of natural experiments and prospective trials have shed new light on long-standing hypotheses. They have also im-

\footnotetext{
${ }^{2}$ No existing theory deals specifically with the interplay between health and education in generating intergenerational persistence. However, Moav (2005) demonstrates how poverty traps can arise when better-educated parents have a comparative advantage in producing educated children. For a broader overview of poverty trap models, see Azariadis and Stachurski (2005).

${ }^{3}$ Several existing papers survey the evidence on the relationship between health and education, but those papers tend to differ in focus from this chapter. Many (e.g., Cutler and Lleras-Muney 2008) exclusively describe research on industrialized countries. Others (e.g., Thomas and Strauss 2008) incorporate evidence from poor countries but touch on education as a one of a much broader set of socioeconomic variables. Still others are centered on a particular causal link, such as the effect of child health on schooling (Glewwe and Miguel 2008), but do not situate that link within a broader causal system.
} 
proved our ability to interpret careful associational studies, which are in many cases more generalizable than experimental studies but less internally valid. These advances have been key to identifying both the direction and the timing of effects in the causal system linking education and health. With this better understanding of what matters and when, policymakers will be better equipped to identify opportunities for well-targeted policies.

\section{Mapping the Relationship between Education and Health}

With its numerous pathways, the causal system linking education and health may seem convoluted. However, one can represent it in a simple but informative diagram. Figure 1 traces out the links between education and health, first over the lifecycle and then across generations. Each arrow represents a causal link that has empirical support in the literature. The solid lines signify intragenerational links - in other words, causal links that operate within a single person-while the dashed lines correspond to links that work across generations within a family.

The system lays out a roadmap for the rest of the chapter. In childhood, good health improves educational outcomes. Additionally, the expectation of good adult health increases schooling investments in childhood. Both health and education persist from childhood to adulthood, at which point education boosts health. But adults are also parents, so their circumstance in middle age spills over onto the next generation. Healthier mothers have healthier children and more educated children. Conversely, parental education promotes both the health and the education of the next generation. At this stage, the causal system repeats in the next generation. In the remainder of the paper, I will focus on the subset of the arrows in Figure 1 that connect health and education. 


\section{$3 \quad$ Intragenerational Links}

\subsection{Effects of Childhood Health on Educational Outcomes}

\subsubsection{Educational Outcomes in Childhood}

We begin in childhood, where abundant evidence suggests that health affects school enrollment and academic achievement. Health enables children to travel to school, concentrate, and think clearly, all of which may improve educational outcomes. Until recently, the evidence has primarily taken the form of cross-sectional associations between children's health and their educational outcomes. Behrman (1996) surveys several such studies from the 1980s and 1990s, which show strong positive relationships between anthropometric measures of child health-such as height-and schooling outcomes in a wide range of settings. ${ }^{4}$ But Behrman ultimately critiques these studies for inadequately addressing issues of causality and omitted variables.

A few analyses published at the same time or after Behrman's critique make some headway on these issues by focusing on within-family variation. Analyzing data from Ghana, Glewwe and Jacoby (1995) estimate models with family fixed effects, finding that shorter siblings start school later than their taller brothers and sisters. More recently, Bharadwaj et al. (2010) analyze twin pairs and sibling sets in Chile, showing that twins or siblings born at higher birth weight perform better on exams. Within-family comparisons of this type eliminate concerns about family-level omitted variables, although they leave some concern about how parents allocate scarce resources among children with observably different health.

\footnotetext{
${ }^{4}$ Because good health and nutrition and in early life are key to optimal physical growth, height serves as a useful retrospective proxy early-life health. Some of the relationship between height and schooling may stem from the effect of early-life health on cognitive development. Researchers have found an association between child height and cognitive test scores in a wide range of settings. For findings from developing countries, see, e.g., Schady and Paxson (2007) and Carvalho (2012).
} 
Analyses of natural experiments in disease eradication, micronutrient supplementation, and health care provision have also made progress on causal identification. ${ }^{5}$ Bleakley (2007), investigating the eradication of hookworm from the U.S. South in the early $20^{\text {th }}$ century, shows that areas with higher initial hookworm burdens saw larger declines in worm infection and larger increases in school enrollment. Using more recent data, Field et al. (2009) study a maternal iodine supplementation program in Tanzania, which the government introduced in different parts of the country at different times. Drawing on policy variation across time and space, as well as on sibling differences in program exposure, they find that in utero exposure to the program increased school participation. Data from Latin America also shed light on the test score impacts of early-life health. Bharadwaj et al. (forthcoming) take advantage of the fact that infants born just below the threshold for very low birth weight (VLBW) receive much more care than those born just above. Using data from Chile (and Norway), they document discontinuities around the VLBW threshold in both infant mortality rates and subsequent test scores, such that infants born below the threshold do better.

In addition to these innovative ways to glean causal effects from observational data, the past decade has seen a series of randomized controlled trials testing the effect of child health on schooling outcomes. Perhaps the best known is a deworming experiment in Busia district, Kenya. Intestinal worms cause anemia and other ailments, which may make children too weak or lethargic to study. To study the effects of worms on schooling outcomes, Miguel and Kremer (2004) experimentally varied access to deworming medications across 75 primary schools in the

\footnotetext{
${ }^{5}$ Several papers from the 1990s and early 2000s use instrumental variables for causal inference, but many of the instruments raise concerns about exclusion restriction violations. These instruments include the distance to the nearest health center (Glewwe and Jacoby 1995), maternal height (Glewwe and Jacoby 1995), and food price variations in early life (Alderman et al. 2001).
} 
district. Pupils in treatment schools exhibited significantly lower rates of worm infection, anemia, and school absence, but not test scores. Experimental data from other settings provide corroborating evidence. In a study of Delhi preschool children, Bobonis et al. (2006) randomized access to iron supplements and deworming medicines across 200 preschools, finding increases in children's weight and school attendance. Attendance effects also emerge in Vermeersch and Kremer's (2004) evaluation of a Kenyan preschool protein supplementation program.

\subsubsection{Educational Outcomes in Adulthood}

The fact that education is relatively fixed by adulthood facilitates the study of its relationship with health. Coupled with retrospective measures of child health, data on adult educational attainment can shed light on the effect of health on education in childhood. For example, just as height and schooling outcomes are associated in children, so too are they related in adults. Adult height positively predicts educational attainment in nationally representative data from Mexico (Vogl 2012), as well as in data on urban populations in Barbados, Mexico, Cuba, Uruguay, Chile, and Brazil (Maurer 2010).

In adulthood, too, the results of natural experiments and randomized controlled trials suggest that the associations partly represent an effect of health on education. One noteworthy finding comes from long-term follow-up of Miguel and Kremer's (2004) deworming experiment in Kenya. In young adulthood, individuals in the treatment group had stayed enrolled in school longer and performed better on a battery of tests than their counterparts in the control group (Baird et al. 2011). On the other hand, long-term follow-up of Bleakley's (2007) study of hookworm in the U.S. South gives different results. To modify his research design to study outcomes in adulthood, Bleakley compares birth cohorts born too early to be exposed to eradication to 
those born later, across areas with differing baseline worm infection prevalence. The results imply significantly positive effects on literacy but not years of schooling.

Several papers have used a similar strategy to estimate the long-term effects of malaria eradication on human capital, with mixed but on net positive results. Bleakley (2010) draws on data from the U.S. South, Brazil, Colombia, and Mexico. Here again, he finds significant effects on literacy but not years of schooling, which he interprets as evidence that eradication makes children more productive as students and as child laborers. ${ }^{6}$ Cutler et al. (2010), applying the same research design to India, recover no evidence of positive effects on either literacy or years of schooling. On the other hand, Lucas (2010) finds positive effects of malaria eradication on both outcomes in Paraguayan and Sri Lankan women.

\subsection{Effect of Life Expectancy on Investment in Education}

Unlike the effect of child health on education, which is rooted in the technology of skill formation, the effect of life expectancy on human capital investment is at its core about optimizing choices by households and individuals. According to the standard reasoning, if an individual expects a longer time horizon to reap the returns to human capital, then that individual will invest more. Analyses of macroeconomic data offer limited support for this hypothesis. Although adult mortality is negatively associated with secondary school enrollment, Lorentzen et al. (2008) find that the relationship is not robust to the inclusion of covariates. However, given the paucity of high-quality data on adult mortality in most countries and the difficulty of assessing causality from cross-country associations, the macroeconomic patterns are suggestive.

\footnotetext{
${ }^{6}$ Barreca (2010) also studies malaria in the U.S., using an identification strategy based on the interaction of regional malaria endemicity and temporal variation in climatic conditions. He estimates that malaria exposure in childhood reduces educational attainment.
} 
Indeed, two microeconomic analyses have yielded convincing evidence that reductions in adult mortality risk increase human capital investment. First, Jayachandran and LlerasMuney (2009) use the near-elimination of maternal mortality in Sri Lanka as a natural experiment in adult mortality. Parts of the country with higher baseline maternal mortality rates (and therefore larger subsequent declines in maternal mortality) saw larger increases in female educational attainment. Second, using data from Africa, Fortson (2011) shows that subnational regions that were hardest hit by the HIV/AIDS epidemic have also experienced the largest declines in education since the start of the epidemic.

\subsection{Effect of Education on Health in Adulthood}

A long-standing literature reports positive associations between education and health in adults in wealthy countries. As Cutler and Lleras-Muney (2008) note in their survey chapter on the topic, the mechanisms linking the two variables are not fully known. To the extent that the association reflects an effect of education on health, important mediators of this effect may include income, working conditions, health-related knowledge, cognitive ability, patience, attitudes towards risk, and cultural capital (especially in interactions with health providers). Similar associations are evident in data from developing countries, although studies are rarer. ${ }^{7}$

Both natural experiments and prospective trials suggest that while education can affect health, such effects may depend on characteristics of the population and the material being taught in school. Several studies use compulsory schooling laws in the U.S. and Europe as

\footnotetext{
${ }^{7}$ See, e.g., Liang et al. (2000) and Zimmer and Kwong (2004) on China; Hurt et al. (2004) on Bangladesh; Wong et al. (2005) on several Latin American cities; and Smith and Goldman (2008) on Mexico. Associations between education and adult health tend to be stronger in urban areas. A notable exception is a study by Fortson (2008) showing a positive relationship between education and HIV infection in several African countries.
} 
instruments for education, with mixed but mildly positive results; some indicate positive effects on health and longevity, while others indicate no effect. ${ }^{8}$ Unfortunately, no similar studies exist on developing countries.

However, longitudinal follow-up of the recent spate of education-related randomized controlled trials in developing countries has begun to yield useful results on health behavior in young adulthood. In one study, Jensen and Lleras-Muney (2012) analyze a program in the Dominican Republic that gave teenage boys information about the return to schooling. The information led the boys to stay in school longer, to delay the onset of heavy drinking, and to reduce smoking at age 18. Across the Atlantic in Africa, Bandiera et al. (2012) estimate the effects of a program that sought to provide adolescent girls with both vocational training and information about risky health behaviors. HIV-related knowledge and condom use both increased. Less promising results have emerged from a Kenyan study on the medium-run impacts of a school subsidy program (Duflo et al. 2012). Although the program increased schooling for both boys and girls, follow-up data show at best weak impacts on sexual behavior and STD infection. Together, these studies suggest that keeping boys 'off the streets' and equipping girls with health information may be key to any effect of education on health in young adulthood.

\section{$4 \quad$ Intergenerational Links}

\subsection{Effect of Parental Education on Child Health}

In the context of poor countries, by far the most widely studied education-health association is that between maternal education and child health. Following Caldwell's (1979) canonical study

\footnotetext{
${ }^{8}$ See, e.g., Lleras-Muney (2005) and Mazumder (2007) on the United States; Arendt (2005) on Denmark; Oreopolous (2007) and Clark and Royer (2010) on the U.K.; and Albouy and Lequien (2009) on France.
} 
of child mortality in Nigeria, a large literature has emerged on this topic. The literature bares widespread correlations between maternal education and child health, measured by illness, anthropometry, or death. ${ }^{9}$ Based on data on Brazilian children's heights, Thomas et al. (1991) argue that educated women's access to information explains much of the correlation.

On the other hand, several studies question the extent to which the correlation reflects a causal effect running from maternal education to child health, as opposed to omitted variables. Desai and Alva (1998) show that the relationship is not always robust to the inclusion of socioeconomic and community-level covariates. Wolfe and Behrman (1987) and Strauss (1990) find that it weakens upon the inclusion of a fixed effect for the mother's sibship or for a multifamily household. However, one could interpret many of Desai and Alva's covariates as mediators of the relationship rather than confounders, and the inclusion of fixed effects exacerbates problems related to measurement error. The results of the revisionist literature are therefore inconclusive.

Analyses of natural experiments support a causal interpretation. The most compelling evidence comes from the United States, where Currie and Moretti (2003) demonstrate that local college openings improve birth weight and gestational age. ${ }^{10}$ But some results are also available for developing countries. Among Indonesian women, for example, exposure to a school construction program reduced mortality rates among their children (Duflo and Breierova 2004). ${ }^{11}$

\subsection{Parental Health Affects Child Education}

Parental health also affects children's schooling outcomes. Two mechanisms stand out in the literature. The first is indirect: healthier mothers have healthier children, who in turn become

\footnotetext{
9 See Cleland and van Ginneken (1988) and references therein.

${ }^{10}$ Currie and Moretti (2003) also show that college openings improve maternal health behaviors.

${ }^{11}$ Notably, Duflo and Breierova (2004) find no differences in the effects of maternal and paternal education.
} 
better-educated adults (Almond and Currie 2011). ${ }^{12}$ For instance, in utero exposure to the 1918 influenza epidemic decreased educational attainment for the cohort born in 1919 in the United States (Almond 2006), Brazil (Nelson 2010), and Taiwan (Lin and Liu 2011). ${ }^{13}$ This effect implies that a mother's health is key to the skill development of her child.

The literature also highlights a second mechanism through which parental health affects child education: parental death. Good evidence comes from the HIV/AIDS epidemic, which has orphaned more than 15 million children (UNAIDS 2010), some 90 percent of them in Africa. Across Africa, orphans have lower school enrollment rates than the biological children of their caretakers (Case et al. 2004). Furthermore, in South Africa (Case and Ardington 2006) and Kenya (Evans and Miguel 2007), the timing of parental death is associated with the timing of school dropout. The same is true in Indonesia (Gertler et al. 2004), where parental deaths typically have little to do to HIV/AIDS. One can thus view the African results as representing a more general effect of losing a parent. Nevertheless, given the scope of the continent's orphan crisis, the results are most relevant there.

\section{$5 \quad$ Open Questions}

The existing literature fills in many of the links sketched in Figure 1, but open questions remain. For one, the distinction between aggregate and individual educational attainment has received little consideration but is almost certainly relevant for health systems in developing countries. How important is a country's education system in producing health professionals to support its

\footnotetext{
${ }^{12}$ On the intergenerational transmission of health in poor countries, see Bhalotra and Rawlings (forthcoming).

${ }^{13}$ Brown (2011) points out that the composition of new parents changed in 1919, which challenges some parts of Almond's (2006) identification strategy.
} 
health system? Additionally, the potential for the backwards intergenerational transmission of health information-from children to parents-remains underexplored. ${ }^{14}$ Such information transmission could prove useful in combatting the rise of smoking and obesity in poor countries (Ezzati and Lopez 2003, Popkin 2008). Concerning intergenerational dynamics in the other direction, from parents to children, the literature would benefit from more focus on how parental behavior reinforces or compensates for exogenous changes in the health environment or educational opportunity. ${ }^{15}$ This last line of inquiry would place behavior back in the center of economic research on health and education.

\section{References}

Adhvaryu, A.R., \& Nyshadham, A. (2012). "Endowments at birth and parents' investments in children." Mimeo, Yale University.

Aizer, A., \& Cunha, F. (2012). “The production of human capital: endowments, investments and fertility." National Bureau of Economic Research Working Paper 18429.

Akresh, R., Bagby, E., De Walque, D., \& Kazianga, H. (2012). “Child ability and household human capital investment decisions in Burkina Faso." Economic Development and Cultural Change 61(1): 157-186.

Alderman, H., Behrman, J.R., Lavy, V., \& Menon, R. (2001). “Child health and school enrollment: A longitudinal analysis." Journal of Human Resources 36(1): 185-205.

Almond, D. (2006). "Is the 1918 Influenza pandemic over? Long-term effects of in utero Influenza exposure in the post-1940 US population." Journal of Political Economy 114(4): 672-712.

\footnotetext{
${ }^{14}$ In one rare example from the historical U.S., Kuziemko (2011) finds that newly-freed slaves learned literacy skills from their children.

${ }^{15}$ See, e.g., Adhvaryu and Nyshadham (2012), Aizer and Cunha (2012), and Akresh et al. (2012).
} 
Almond, D., \& Currie, J. (2011). “Human capital development before age five." In O. Ashenfelter and D. Card, eds., Handbook of Labor Economics, Vol. 4A. Amsterdam: North Holland, pp. 1315-1486.

Arendt, J.N. (2005). “Does education cause better health? A panel data analysis using school reforms for identification." Economics of Education Review 24(2): 149-160.

Azariadis, C., \& Stachurski, J. (2005). "Poverty traps." In P. Aghion and S.N. Durlauf, eds., Handbook of Economic Growth. Amsterdam: North Holland, pp. 295-384.

Baird, S., Hicks, J.H., Kremer, M., \& Miguel, E. (2011). “Worms at work: long-run impacts of child health gains." Mimeo, University of California, Berkeley.

Bandiera, O., N. Buehren, R. Burgess, M. Goldstein, S. Gulesci, I. Rasul \& M. Sulaiman. (2012). "Empowering adolescent girls: Evidence from a randomized control trial in Uganda." Mimeo, London School of Economics.

Barreca, A.I. (2010). “The long-term economic impact of in utero and postnatal exposure to malaria." Journal of Human Resources 45(4): 865-892.

Barro, R.J., \& Lee, J.W. (2010). “A new data set of educational attainment in the world, 19502010." National Bureau of Economic Research Working Paper 15902.

Becker, G.S., Philipson, T.J., \& Soares, R.R. (2005). “The quantity and quality of life and the evolution of world inequality." American Economic Review 95(1): 277-291.

Behrman, J.R. (1996). “The impact of health and nutrition on education." World Bank Research Observer 11(1): 23-37.

Behrman, J.R., \& Wolfe, B.L. (1987). “How does mother's schooling affect family health, nutrition, medical care usage, and household sanitation?" Journal of Econometrics 36(1): 185-204.

Bhalotra, S., \& Rawlings, S.B. (Forthcoming). Gradients of the Intergenerational Transmission of Health in Developing Countries. Review of Economics and Statistics.

Bharadwaj, P., Eberhard, J., \& Neilson, C. (2010). “Do initial endowments matter only initially? The persistent effect of birth weight on school achievement." University of California at San Diego Economics Working Paper 1562347. 
Bharadwaj, P., Løken, K., \& Neilson, C. (Forthcoming). Early life health interventions and academic achievement. American Economic Review.

Björklund, A., \& Salvanes, K.G. (2011). “Education and family background: Mechanisms and policies." In E. Hanushek and F. Welch, eds., Handbook of the Economics of Education, Vol. 3. Amsterdam: North Holland, pp. 201-247.

Bleakley, H. (2007). Disease and development: evidence from hookworm eradication in the American South. Quarterly Journal of Economics 122(1): 73-117.

Bleakley, H. (2010). "Malaria eradication in the Americas: A retrospective analysis of childhood exposure." American Economic Journal: Applied Economics 2(2): 1-45.

Bobonis, G.J., Miguel, E., \& Puri-Sharma, C. (2006). “Anemia and school participation.” Journal of Human Resources 41(4): 692-721.

Brown, R. (2011). “The 1918 U.S. influenza pandemic as a natural experiment, revisited." Mimeo, Duke University.

Caldwell, J.C. (1979). “Education as a factor in mortality decline an examination of Nigerian data." Population Studies 33(3): 395-413.

Carvalho, L.S. (2012). "Childhood circumstances and the intergenerational transmission of socioeconomic status." Demography 49(3): 913-938.

Case, A., Paxson, C., \& Ableidinger, J. (2004). “Orphans in Africa: parental death, poverty, and school enrollment." Demography 41(3): 483-508.

Case, A., and C. Ardington. (2006). "The impact of parental death on school enrollment and achievement: Longitudinal evidence from South Africa.” Demography 45 (3): 401-402.

Clark, D., \& Royer, H. (2010). “The effect of education on adult health and mortality: Evidence from Britain." National Bureau of Economic Research Working Paper 16013.

Cleland, J.G., \& Van Ginneken, J.K. (1988). "Maternal education and child survival in developing countries: the search for pathways of influence." Social Science $\mathcal{E}$ Medicine 27(12): 13571368. 
Currie, J., \& Moretti, E. (2003). "Mother's education and the intergenerational transmission of human capital: Evidence from college openings." Quarterly Journal of Economics 118(4): 14951532.

Currie, J., \& Vogl, T. (Forthcoming). “Early-life health and adult circumstance in developing countries." Annual Review of Economics.

Cutler, D.M., \& Lleras-Muney, A. (2010). “Understanding differences in health behaviors by education." Journal of Health Economics 29(1): 1-28.

Cutler, D., \& Lleras-Muney A. (2008). "Education and Health: Evaluating Theories and Evidence." In J. House, R. Schoeni, G. Kaplan, H. Pollack, eds., Making Americans Healthier: Social and Economic Policy as Health Policy. New York: Russell Sage Foundation.

Cutler, D.M., Fung W., Kremer M., Singhal M., Vogl T. (2010). “Early life malaria exposure and adult outcomes: evidence from malaria eradication in India." American Economic Journal: Applied Economics 2(2): 196-202.

Cutler, D.M., Lange, F., Meara, E., Richards-Shubik, S., \& Ruhm, C.J. (2011). “Rising educational gradients in mortality: The role of behavioral risk factors." Journal of Health Economics 30(6): 1174-1187.

Desai, S., \& Alva, S. (1998). “Maternal education and child health: Is there a strong causal relationship?" Demography 35(1): 71-81.

Duflo. E., \& Breierova, L. (2004). “The impact of education on fertility and child mortality: Do fathers really matter less than mothers?" National Bureau of Economic Research Working Paper 10513.

Duflo, E., Dupas, P., \& Kremer, M. (2012). “Education, HIV and early fertility: Experimental evidence from Kenya." Mimeo, Stanford University.

Evans, D.K., \& Miguel, E. (2007). “Orphans and schooling in Africa: A longitudinal analysis." Demography 44(1): 35-57.

Ezzati, M., \& Lopez, A.D. (2003). "Estimates of global mortality attributable to smoking in 2000." Lancet 362(9387): 847-852. 
Field, E., Robles, O., \& Torero, M. (2009). “Iodine deficiency and schooling attainment in Tanzania." American Economic Journal: Applied Economics 1(4): 140-169.

Fortson, J.G. (2008). "The gradient in sub-Saharan Africa: socioeconomic status and HIV/AIDS." Demography 45(2): 303-322.

Fortson, J.G. (2011). “Mortality risk and human capital investment: The Impact of HIV/AIDS in Sub-Saharan Africa." Review of Economics and Statistics 93(1): 1-15.

Gertler, P., Levine, D.I., \& Ames, M. (2004). “Schooling and parental death." Review of Economics and Statistics 86(1): 211-225.

Glewwe, P., \& Jacoby, H.G. (1995). “An economic analysis of delayed primary school enrollment in a low income country: The role of early childhood nutrition." Review of Economics and Statistics 77(1): 156-169.

Hurt, L.S., Ronsmans, C., \& Saha, S. (2004). "Effects of education and other socioeconomic factors on middle age mortality in rural Bangladesh." Journal of Epidemiology and Community Health 58(4): 315-320.

Jayachandran, S., \& Lleras-Muney, A. (2009). "Life expectancy and human capital investments: Evidence from maternal mortality declines." Quarterly Journal of Economics 124(1): 349-397.

Jensen, R., \& Lleras-Muney, A. (2012). “Does staying in school (and not working) prevent teen smoking and drinking?" Journal of Health Economics 31(4): 644-675.

Krueger, A.B and Lindhal, M. (2001). "Education for growth: Why and for whom?" Journal of Economic Literature 6(2): 289-339.

Kuziemko, I. (2011). "Human capital spillovers in families: Do parents learn from or lean on their children?" National Bureau of Economic Research Working Paper 17235.

Liang, J., McCarthy, J.F., Jain, A., Krause, N., Bennett, J.M., \& Gu, S. (2000). "Socioeconomic gradient in old age mortality in Wuhan, China." Journal of Gerontology Series B: Psychological Sciences and Social Sciences 55(4): s222-s233. 
Lin, M.J., \& Liu, E.M. (2012). "Does 'in utero' exposure to illness matter? The 1918 influenza epidemic in Taiwan as a natural experiment." Mimeo, University of Houston.

Lleras-Muney, A. (2005). "The relationship between education and adult mortality in the United States." Review of Economic Studies 72(1): 189-221.

Lorentzen, P., McMillan. J., \& Wacziarg. R. (2008). “Death and development.” Journal of Economic Growth 13(2): 81-124.

Lucas, A.M. (2010). "Malaria eradication and educational attainment: Evidence from Paraguay and Sri Lanka." American Economic Journal: Applied Economics 2(2): 46-71.

Mazumder, B. (2005). "Fortunate sons: New estimates of intergenerational mobility in the United States using Social Security earnings data." Review of Economics and Statistics 87(2): 235-255.

Maurer, J. (2010). “Height, education and later-life cognition in Latin America and the Caribbean." Economics \& Human Biology 8(2): 168-176.

Miguel, E., \& Kremer, M. (2003). “Worms: identifying impacts on education and health in the presence of treatment externalities." Econometrica 72(1): 159-217.

Albouy, V., \& Lequien, L. (2009). “Does compulsory education lower mortality?" Journal of Health Economics 28(1): 155-168.

Miguel, E., \& Glewwe, P. (2008). “The impact of child health and nutrition on education in less developed countries." In T.P. Schultz and J.A. Strauss, eds., Handbook of Development Economics Vol. 4. Amsterdam: North Holland, pp. 3561-3606.

Moav, O. (2005). “Cheap children and the persistence of poverty." Economic Journal 115(500): 88110.

Nelson, R.E. (2010). "Testing the fetal origins hypothesis in a developing country: Evidence from the 1918 influenza pandemic." Health Economics 19(10): 1181-1192.

Oreopoulos, P. (2007). "Do dropouts drop out too soon? Wealth, health and happiness from compulsory schooling." Journal of Public Economics 91(11): 2213-2229. 
Paxson, C., \& Schady, N. (2007). “Cognitive development among young children in Ecuador the roles of wealth, health, and parenting." Journal of Human Resources 42(1): 49-84.

Popkin, B.M. (2008). "The nutrition transition: an overview of world patterns of change." Nutrition Reviews 62(s2): s140-s143.

Smith, K.V., \& Goldman, N. (2008). "Socioeconomic differences in health among older adults in Mexico." Social Science E Medicine 65(7): 1372-1385.

Strauss, J. 1990. "Household, community and preschool child nutrition outcomes: Evidence from rural Côte d'Ivoire." Economic Development and Cultural Change 38(2): 231-61.

Thomas, D., Strauss, J., \& Henriques, M.H. (1991). “How does mother's education affect child height?" Journal of Human Resources 26(2): 183-211.

UNAIDS. (2010). Global Report: UNAIDS Report on the Global AIDS Pandemic: 2010. Online: http://www.unaids.org/documents/20101123 globalreport em.pdf.

Vermeersch, C., \& Kremer, M. (2005). "School meals, educational achievement, and school competition: evidence from a randomized evaluation." World Bank Policy Research Working Paper 3523.

Vogl, T. (2012). "Height, Skills, and Labor Market Outcomes in Mexico." National Bureau of Economic Research Working Paper 18318.

Wong, R., Peláez, M., \& Palloni, A. (2005). "Self-reported general health in older adults in Latin America and the Caribbean: usefulness of the indicator." Revista Panamericana de Salud Pública 17(5-6): 323-332.

Zimmer, Z., \& Kwong, J. (2004). "Socioeconomic status and health among older adults in rural and urban China." Journal of Aging and Health 16(1): 44-70. 
Figure 1: Causal Links between Health and Education

Childhood $\underline{\text { Adulthood } \quad \text { Childhood }}$

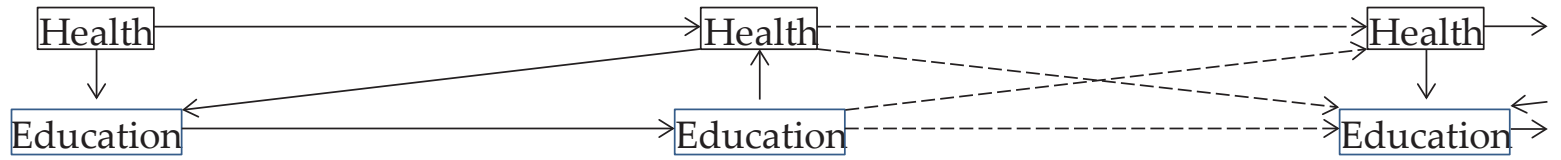

Generation $t$

Generation $t+1$

Intragenerational links $\longrightarrow$

Intergenerational links $\quad-\cdots-\cdots$ 